\title{
Code and Software: How would YOU share yours?
}

IN43C-0902, AGU Fall Meeting - 13 December 2018

Mathew Biddle, Nancy Copley, Tina Haskins, Danie Kinkade, Shannon Rauch, Mak Saito, Adam Shepherd, Karen Soenen, Peter Wiebe, and Amber York | Woods Hole Oceanographic Institution

BCO-DMO curates earth science data where models
become increasingly important
The Biological and Chemical Oceanography Data Management Office (BCO-DMO) is a
publicly accessible earth science data repository created to curate, publicly serve
(publish), and archive digital data and information from biological, chemical and
biogeochemical research conducted in coastal, marine, great lakes and laboratory
environments. Recently, more and more of the projects submitted to BCO-DMO
represent modeling efforts which further increase our knowledge of the chemical
and biological properties within the ocean ecosystem. We feel the time is at hand for
the scientific community to begin a concerted and holistic approach to the curation
of code and software.
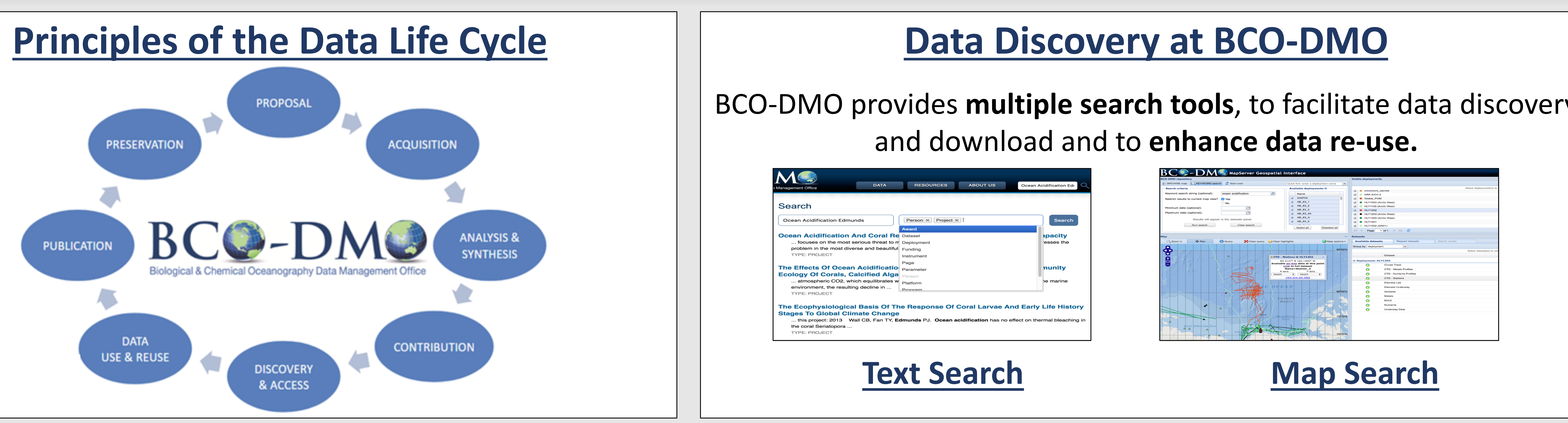

We want to help and support the scientific community to better manage code and make it a first class research asset. Your opinion matters! The questions below will inform BCO-DMO of the scientific community needs.

- What pieces of information should we curate?

- Model inputs? Model outputs?

- For community accepted models, should we simply provide discovery?

- At what point should the code be curated?

- During development? Once research has been published? During revisions of code?

- Model vs post-processing scripts?

- Code for the entire model?

- Post-processing scripts which acted on the output?

- Should the results of model research be treated the same as physical observations?

- Do we need to store the output or just the code?

- Facilitate peer review of code?

- Should repositories be responsible for code re-use?

\section{Question B: What information do you find useful to re-using code or modeling methods?}

Input files

ROMS_INPUT_FILES

四点哭 $\vee *$

constant_river_frc.nc

riverfirc.nc

ROMS_grid_upper_c....ThetaB1.0_Tcline10.nc

sedimentin

upper_ches_ocean_i...B1.0_TCline10_sed1.nc

upper_ches_ocean_i...B1.0_Tcline10_eded2nc

vegetation.in

Full resolution output

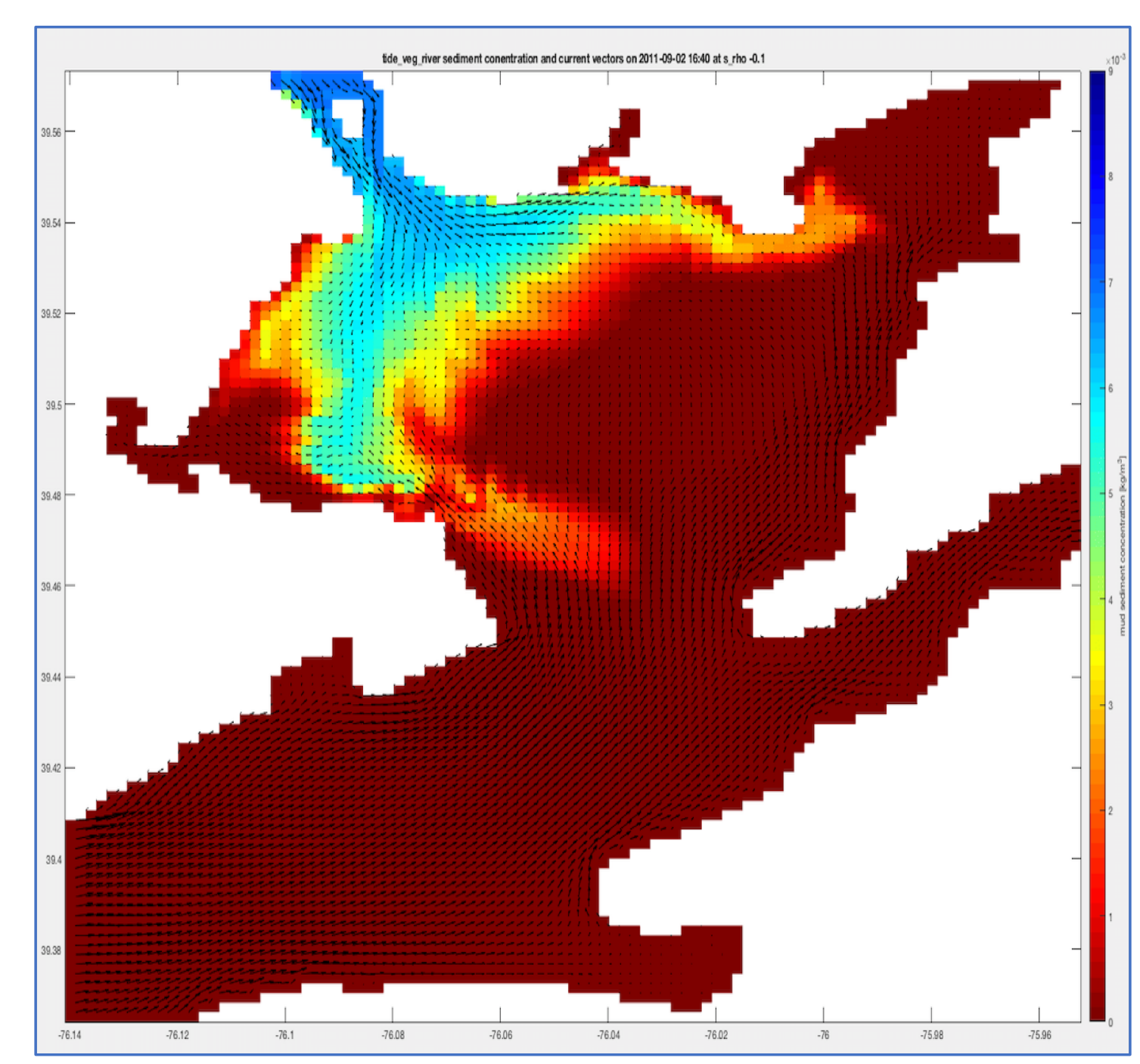

Metadata elements

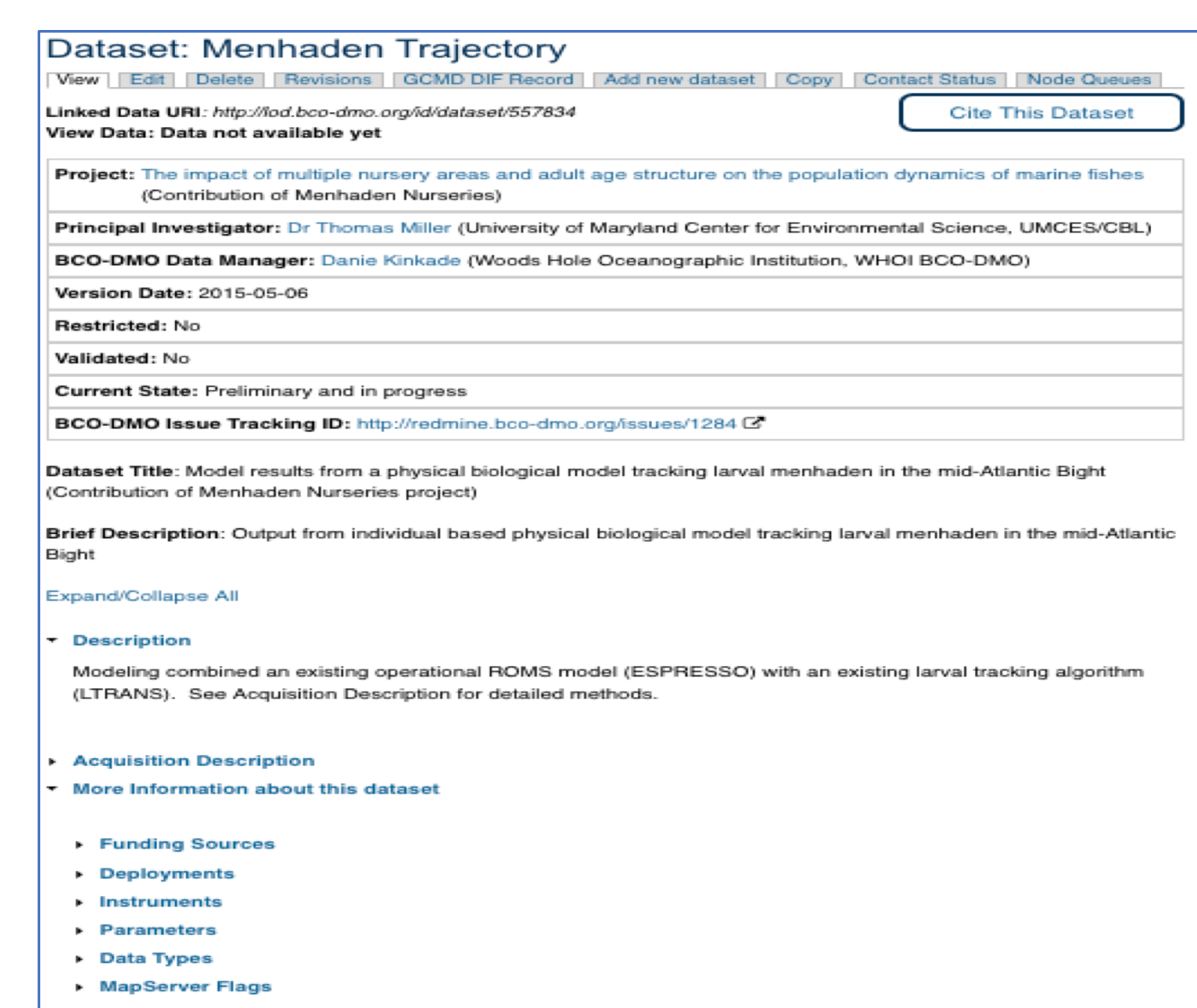

Question C: How do you want to access your code?

Raw files

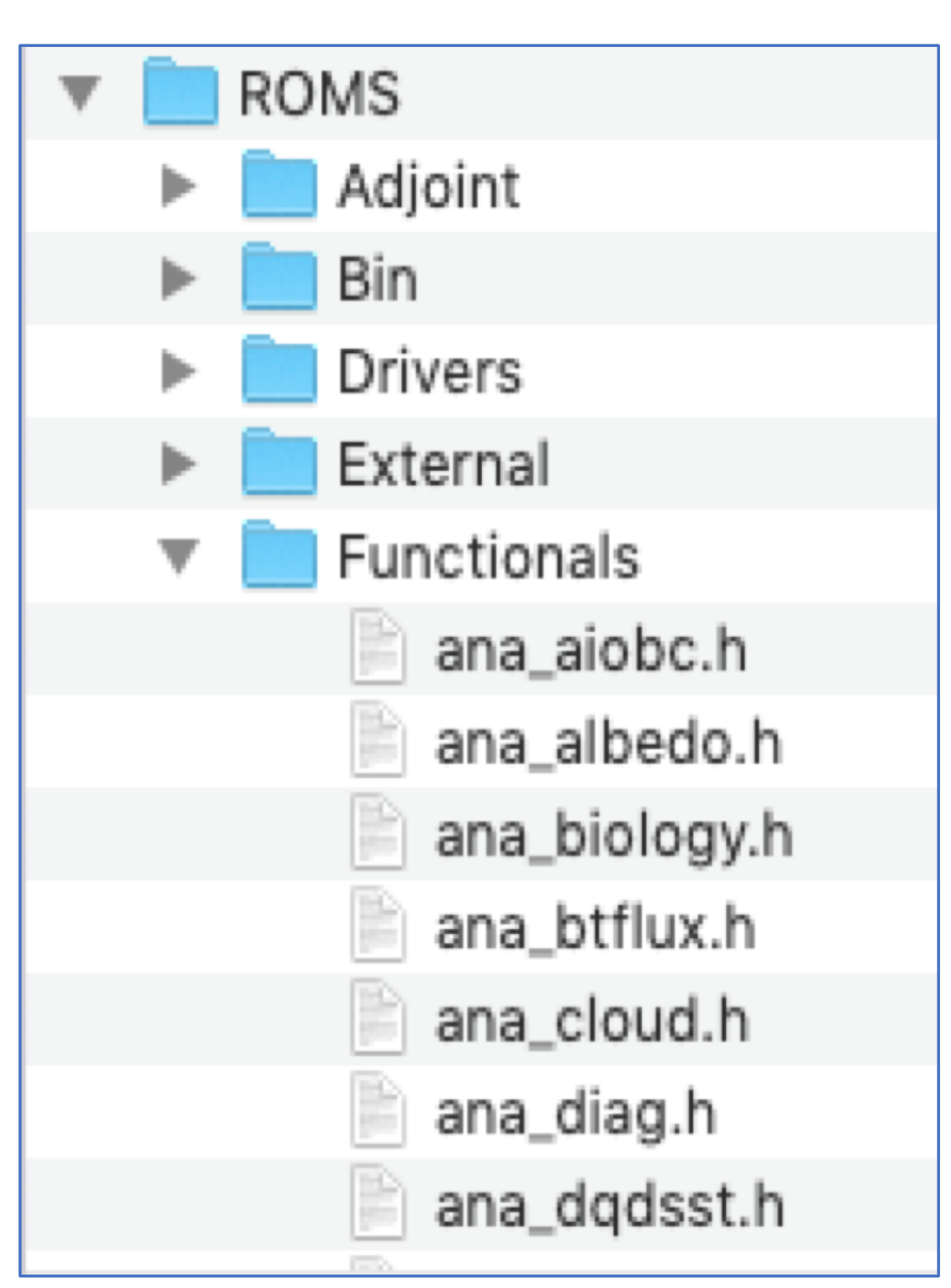

Code repository/persistent identifier?

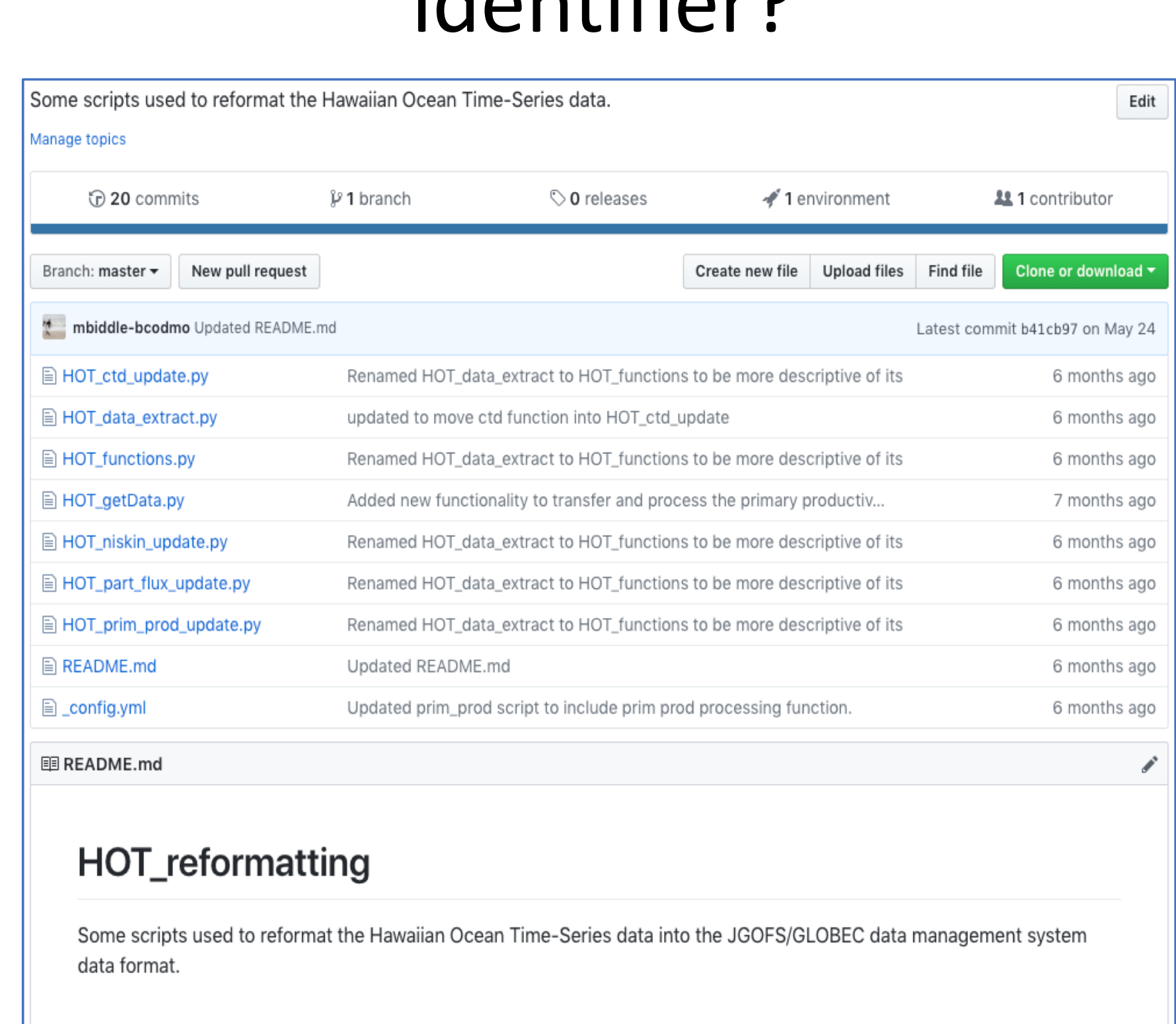

Interactive environment

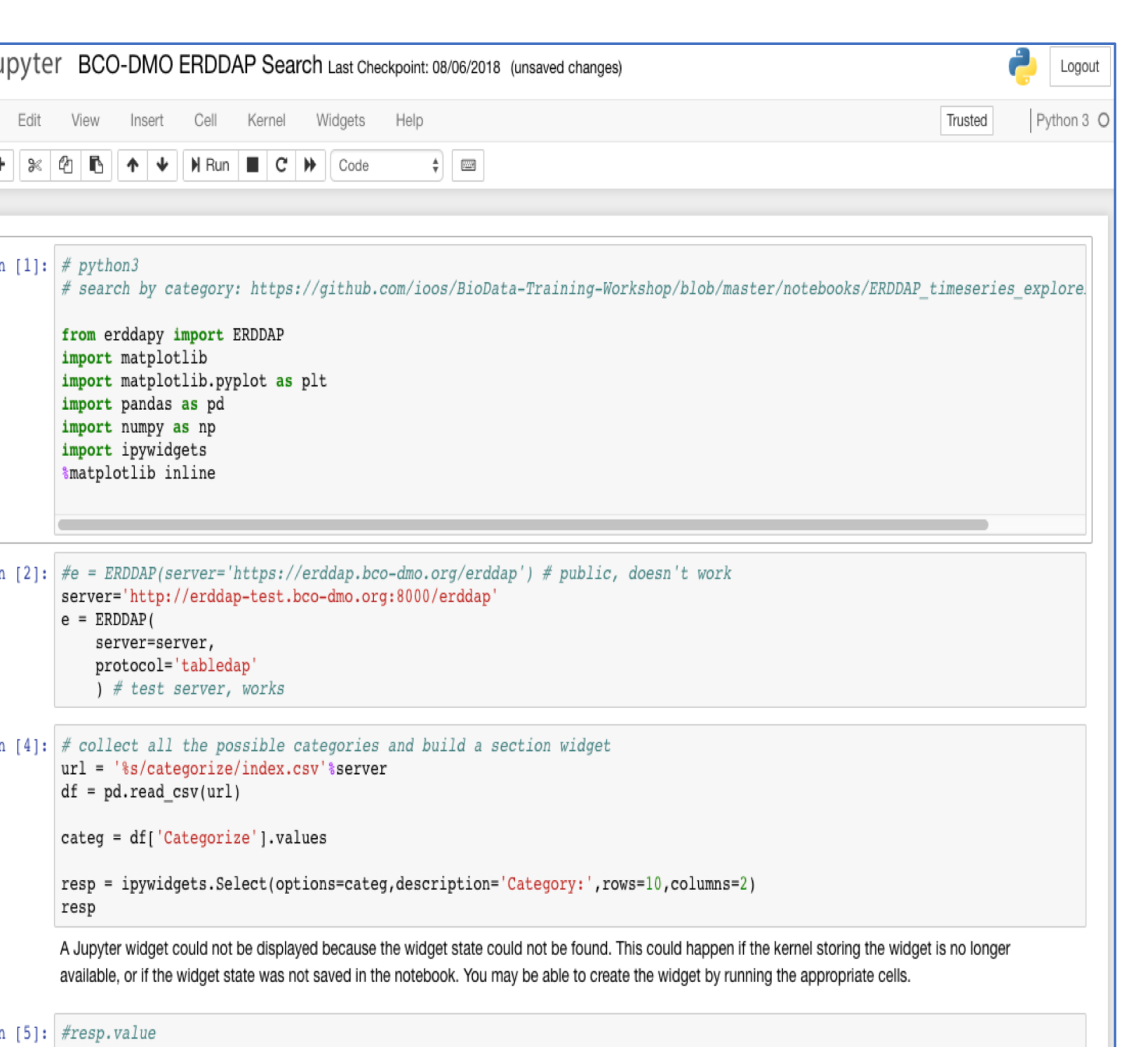

Make your opinion clear by:

- Using the stickies on the right to add your thoughts on the questions.

- Include your name, e-mail, and what your role is at your institution (publisher, funder, researcher, repository?)

Indicate which of the parts of the two sections, $B$ \& $C$, you think would be the most beneficial to the community 